\title{
Comparison of Two Bar Edge Lengths of Refining Plates on the Properties of American Old Corrugated Container Pulp during Low Consistency Refining
}

\author{
Hui Cai, ${ }^{\text {a,b,c }}$ Zhaoyang Yuan,,${ }^{c, d, *}$ Guolin Tong, ${ }^{\text {a }}$ Xin Zhang, ${ }^{a}$ and Hui Zhang ${ }^{\text {a,* }}$ \\ Commercial American old corrugated container pulp (AOCC) boards were \\ used as the starting material for repulping and low consistency (LC) \\ refining to investigate the effects of $L C$ refining plate geometry on the fibre \\ and strength properties of the generated pulp. Specific refining energy that \\ ranged from 0 to $120 \mathrm{kWh} /$ air-dried ton (ADT) of pulp was explored for the \\ two bar edge lengths (BEL) of refining plate patterns, wide $0.99 \mathrm{~km} / \mathrm{rev}$ \\ $B E L$ and interim $2.01 \mathrm{~km} / \mathrm{rev} B E L$. The results showed that fibre length, \\ curl index, kink index, and pulp freeness decreased while fines content \\ increased with increasing refining energy input for both of the two refining \\ plates during LC refining. LC refining with 2.01 BEL plate at low intensity \\ of $0.24 \mathrm{~J} / \mathrm{m}$ showed less fibre length reduction and more tensile strength \\ development than that obtained with $0.99 \mathrm{BEL}$ plate at high intensity of \\ $0.48 \mathrm{~J} / \mathrm{m}$ when compared at the same specific energy. Moreover, to \\ achieve the desired tensile strength of the AOCC pulp, lower energy was \\ needed for the interim 2.01 BEL plate than the wide 0.99 BEL plate. Thus, \\ the interim $2.01 \mathrm{~km} / \mathrm{rev}$ BEL refining plate provided potential for saving \\ refining energy to reach a desired tensile strength of AOCC pulp.
}

Keywords: LC refining; AOCC pulp; Refiner plate geometries; Fibre properties; Tensile strength

Contact information: a: Jiangsu Provincial Key Lab of Pulp and Paper Science and Technology, Nanjing Forestry University, Nanjing, 210037, China; b: State Key Laboratory of Pulp and Paper Engineering, South China University of Technology, Guangzhou, 510640, China; c: Pulp and Paper Centre, University of British Columbia, 2385 East Mall, Vancouver, British Columbia, V6T 1Z4, Canada; d: Department of Chemical \& Biological Engineering, University of British Columbia, 2360 East Mall, Vancouver, British Columbia,V6T 1Z4, Canada; *Corresponding author: yuanzy87@hotmail.com; njfuzhangh@163.com

\section{INTRODUCTION}

The increasing demand for packaging papers has motivated the utilization of recycled old corrugated container (OCC) as the raw material for the production of paper boards and corrugating mediums for various packaging purposes (Kang et al. 2017). Different from the virgin fibres from wood or other lignocellulosic materials, recycled OCC has relatively lower strength due to hornification of fibres (Fernandes Diniz et al. 2004; Hubbe et al. 2007). To overcome the strength reduction of the recycled fibres, considerable efforts and technological approaches have been conducted (Gurnagul 1995; Viesturs et al. 1996; Oliveux et al. 2015). However, most previous studies have focused on the improvement of paper strength, water resistance value, and paper machine speed by adding different types of papermaking additives (Bajpai 2015). In addition, although refining is recognized to be an important stage and has been widely investigated during papermaking, the studies on understanding the fundamental properties of OCC pulp such as the evolution of fibre morphology and pulp freeness during refining are limited. 
Compared to Chinese OCC pulp, American OCC (AOCC) pulp generally has longer fibre and higher pulp strength due to the lower number of recycled times (Cai et al. 2017). Thus, AOCC could be an appropriate raw material for the replacement of a portion of original pulp for the production of high-grade products such as high-strength packaging paper (Hunt and Vick 2004). To prepare OCC pulp, refining is a mechanical strategy to improve the bonding properties of the fibres in the pulp, in turn, improving the paper properties such as tensile strength (Nugroho 2012). Additionally, the appropriate refining technology, such as low consistency (LC) refining, could also alleviate the problems caused by the variability in the collection of used corrugated containers and improve the drainage of the obtained pulp, thereby providing a potential to increase the output capacity of the papermaking machine (Gorski et al. 2012).

During the refining process, fibres undergo various structural changes including increased fibre swelling, fibre shortening, fines formation, fibre straightening, as well as internal and external fibrillation (Ingmanson and Thode 1959; Gharehkhani et al. 2015; Rubiano Berna et al. 2018). The refining process is also recognized as a process of energy conversion, in which electrical energy is converted into mechanical energy to make changes on the fibres. To describe the refining process, the term refining theory, aiming at predicting changes in pulp properties from known refining conditions, has been proposed since the early 1920s (Gominho and Pereira 1995; Sain et al. 2002). The theory reported by Smith (1922) was completely based on visual observation of the refining process and lacked experimental support. With the improvement of experimental devices and research methods, some new refining theories have been put forward due to the deeper understanding of the refining mechanism. This understanding includes specific edge load (SEL) theory (Wultsch and Flucher 1958; Prairie et al. 2008), specific surface load (SSL) theory (Lumiainen 1990), and C-factor theory (Kerekes 1990). To the best of the authors' knowledge, the most widely used refining theory is the SEL theory, which comprises only simple calculations (equations), such as specific refining energy (SRE), SEL, and bar edge length (BEL), in which all parameters are readily available. The SEL is determined by the net power divided by the BEL multiplied by the rotational speed (Wultsch and Flucher 1958). The SEL theory helps experienced papermakers know approximately what kind of fillings and specific edge load should be used when refining certain pulp at a given consistency.

LC refining, which is typically conducted at a fibre consistency of approximately $4 \%(\mathrm{w} / \mathrm{v})$, has been reported to be a more effective strategy for saving refining energy compared to that of high consistency (HC) refining with a refining consistency of approximately $40 \%$ (w/v) (Muenster et al. 2005). For LC refining, the refining plate is normally grooved so that the bars treat the fibres and the grooves between bars allow fibre transportation through the machine (Sixta 2008). Once refining starts, fibre flocs are first collected on the leading edge of the stator bar and then compressed when the leading edge of the rotor bar approaches the leading edge of the stator bar. Simultaneously, short fibres with low flocculation ability are peeled off and flow into the grooves between the bars, resulting in most of the long fibres remaining in the bar zone to receive refining.

Although substantial work has been conducted on developing different patterns of refining plates to increase the overall efficiency on the utilization of electrical energy to improve fibre morphology (Olson et al. 2003; Gorski et al. 2010), limited work has been conducted with recycled OCC pulp. Due to the different characteristics, such as fibre length, fines content, and curl index between virgin fibres and recycled OCC fibres, it is of great importance to investigate the effects of the refining process on the change of fibre 
properties of OCC pulp. This not only provides marginal insights into the mechanism of refining of OCC pulp, but also improves the papermaking process with using OCC pulp as the raw material. Additionally, the investigation of refining OCC pulp might be able to provide potential in seeking an effective strategy for energy saving during processing recycled corrugated containers. This work preliminary investigated the effect of refining AOCC pulp with two kinds of refining plates, wide $0.99 \mathrm{~km} / \mathrm{rev}$ bar edge length (BEL) plate and interim 2.01 BEL km/rev plate, on the properties of fibre, such as freeness, fibre length, and tensile strength, of the produced paper sheets. The main objective of this study is to expand the application of AOCC pulp in various grades of paper products such as linerboard, corrugating medium, and folding boxboard.

\section{EXPERIMENTAL}

\section{Materials}

The AOCC was provided by Norampac Co., Ltd. (Richmond, Canada). The obtained commercial AOCC were torn into pieces (10 to $15 \mathrm{~mm}$ in width and 12 to $17 \mathrm{~mm}$ in length). The obtained pieces of AOCC were stored at room temperature for further utilization.

\section{Low Consistency Refining}

The LC refining experiment was conducted at the Pulp and Paper Centre of University of British Columbia (BC, Canada). Before LC refining, the AOCC pieces were soaked in deionized water at a solids consistency of $4.0 \%$ for $24 \mathrm{~h}$ and then repulped (AFT; Sherbrooke, Quebec, Canada) for $24 \mathrm{~min}$ at $3.2 \%$ pulp consistency to produce AOCC pulp. During the pilot-scale repulping process, the refining plate $(0.99 \mathrm{~km} / \mathrm{rev}$ BEL and 2.01 $\mathrm{km} / \mathrm{rev}$ BEL) was installed into the repulping system. Thus, the fibres might have become slightly refined before engagement of the refiner plate as the pulp was passing through the system. Pulps with same freeness were selected when studying the repulping process (as $\mathrm{SRE}=0$ ) to investigate the effects of the refining plates on the properties of the refined pulps. For the refining process, the pulp at $3.2 \%$ consistency was passed through a 16-inch single disk refiner by pumping the pulp through the refiner at a specific energy of $20 \mathrm{kWh} / \mathrm{t}$. The pulp suspension was refined at a target of SEL of 0.48 and $0.24 \mathrm{~J} / \mathrm{m}$ for 0.99 BEL plate and 2.01 BEL plate, respectively. The pulp was then sampled before passing through the refiner again at the same specific energy. The process was repeated six times to a total specific energy of $120 \mathrm{kWh} / \mathrm{t}$. While running the refiner, other refining process parameters were always kept constant for every different plate. The schematic of the LC refining system is illustrated in Fig 1. All the LC refining trials were completed with targets of 1200 $\mathrm{rpm}$ refiner speed, pulp volumetric flow rate of approximately $250 \mathrm{~L} / \mathrm{min}$, and $3.2 \%$ pulp consistency. The refined pulps were collected and stored at $4{ }^{\circ} \mathrm{C}$ until further experimentation. Table 1 shows the refiner plate geometries used in this study. The refiner disks had a common outer diameter of $406 \mathrm{~mm}$ and inner diameter of $229 \mathrm{~mm}$. Both refiner plates had a groove depth of $4.8 \mathrm{~mm}$ and bar angle of $15^{\circ}$. For each trial, the temperature of pulp after repulping was also measured. All experiments were performed at least in triplicate. 
Table 1. Summary of LC Refining Plate Geometries Used

\begin{tabular}{|c|c|c|c|c|c|}
\hline Trial & Bar Type & $\begin{array}{c}\text { BEL } \\
(\mathrm{km} / \mathrm{rev})\end{array}$ & Bar Width $(\mathrm{mm})$ & $\begin{array}{c}\text { Groove Width } \\
(\mathrm{mm})\end{array}$ & Temperature $\left({ }^{\circ} \mathrm{C}\right)$ \\
\hline 1 & Wide & 0.99 & 3.2 & 4.8 & 45.4 \\
\hline 2 & Interim & 2.01 & 2.0 & 3.6 & 42.7 \\
\hline
\end{tabular}

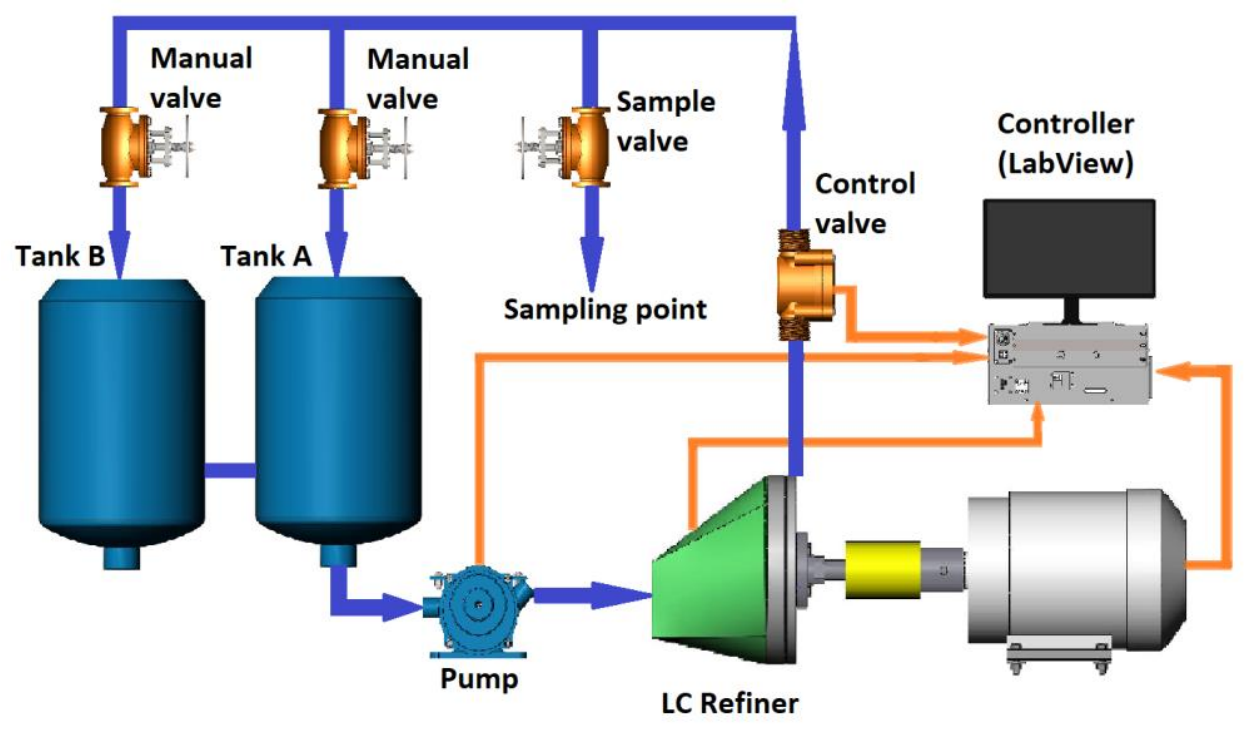

Fig. 1. The schematic of LC refining system

\section{Analytical Methods}

The moisture content of solid samples was measured by drying at $105 \pm 2{ }^{\circ} \mathrm{C}$ to constant weight. The freeness of pulps was tested according to TAPPI method T227 om99 (1999). Pulp properties of length-weighted fibre length, curl index, kink index, and fines content were determined with a fibre quality analyzer (FQA; OpTest Equipment Inc., Hawkesbury, Canada) following the ISO 16065 (2014) standard. Briefly, a total of 2 to 4 mg oven-dried (o.d.) pulp samples were diluted with $600 \mathrm{~mL}$ deionized water and mixed for $5 \mathrm{~min}$ for the measurement with the FQA. The fibre morphology was observed with a light microscope (Microflex HFX-II; Nikon, Tokyo, Japan) at 400× magnification. The procedure for using this equipment was based on the manual for the Nikon microscope PPCT 1020. A pulp handsheet with a grammage of $60 \mathrm{~g} / \mathrm{m}^{2}$ was prepared according to TAPPI T205 sp-02 (2002) standard. The prepared handsheets were air-dried in a constant temperature and humidity room $\left(23.0{ }^{\circ} \mathrm{C}, 48.5 \%\right.$ relative humidity) for $24 \mathrm{~h}$ prior to measuring the strength and optical properties. Tensile strength was determined according to the TAPPI T494 (2006) method using an L\&W tensile strength tester.

\section{Statistical Analysis}

Data collected from triplicate measurements were analyzed by a one-way analysis of variance (ANOVA) using the Origin software (OriginLab Corporation, Origin85, Northampton, MA, USA). Multiple comparisons among treatments were performed using the Tukey post hoc test. Significant differences between treatments were evaluated at $\mathrm{p} \leqslant$ 0.05. Error bars in all graphs are $95 \%$ confidence intervals. 


\section{RESULTS AND DISCUSSION}

\section{Mechanical Fibrillation}

To evaluate the effects of refining on the properties of the AOCC pulp, LC refining was conducted on the pulp. Figure 2 shows the effect of the refining process on the properties of the obtained pulp. It needs to be noted that due to the different patterns of the refining plate installed during the repulping process, the fibre length and fines percentage of the fibre suspension at SRE $=0$ might be different even at the same pulp freeness. Figure 2a shows that, as anticipated, the average weighted fibre length decreased with increasing refining energy for both the $0.99 \mathrm{BEL}$ and $2.01 \mathrm{BEL}$ plates. This could be attributed to the fibre shortening created by refining/beating (Sjoberg and Hoglund 2007). Figure 2a also reveals that the refining with $2.01 \mathrm{BEL}$ plates generally resulted in higher fibre length than that of the $0.99 \mathrm{BEL}$ plate under the same refining energy. One likely reason might be that plate 2.01 BEL is a low-intensity interim plate that produced less fibre cutting than plate 0.99 BEL (Olson et al. 2003).
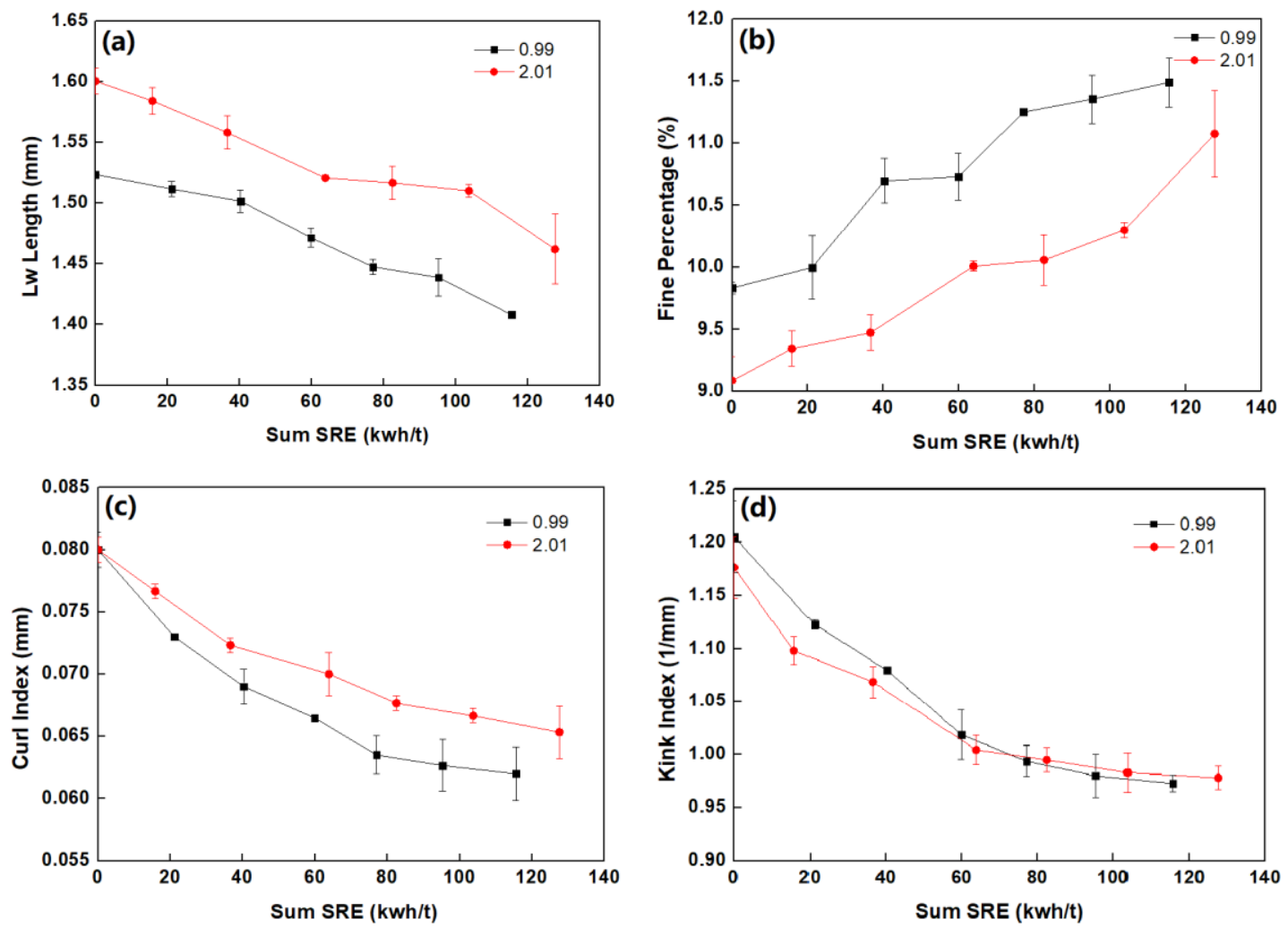

Fig. 2. The pulp properties development during LC refining: (a) the development of lengthweighted fibre length versus sum SRE; (b) the development of fine percentage versus sum SRE; (c) the development of curl index versus sum SRE; and (d) the development of kink index versus sum SRE

The content of fines in the refined pulp was determined (Fig. 2b). To further assess the fibre cutting during the refining process, the fibre length distribution of the AOCC pulp during the LC refining was investigated and is given in Fig. 3. As shown in both Fig. 2b and Fig. 3, the content of fines gradually increased with increasing SRE used for refining. Moreover, the fines content in the pulps obtained from the refining with the 2.01 BEL plate 
was much lower than that of the $0.99 \mathrm{BEL}$ plate. This was in accordance with the results of Fig. 2a. These results demonstrated that the refining with the 2.01 BEL plate had the potential to preserve fibre length, in turn reducing the amount of short fibre fragments in the pulp suspension after refining.
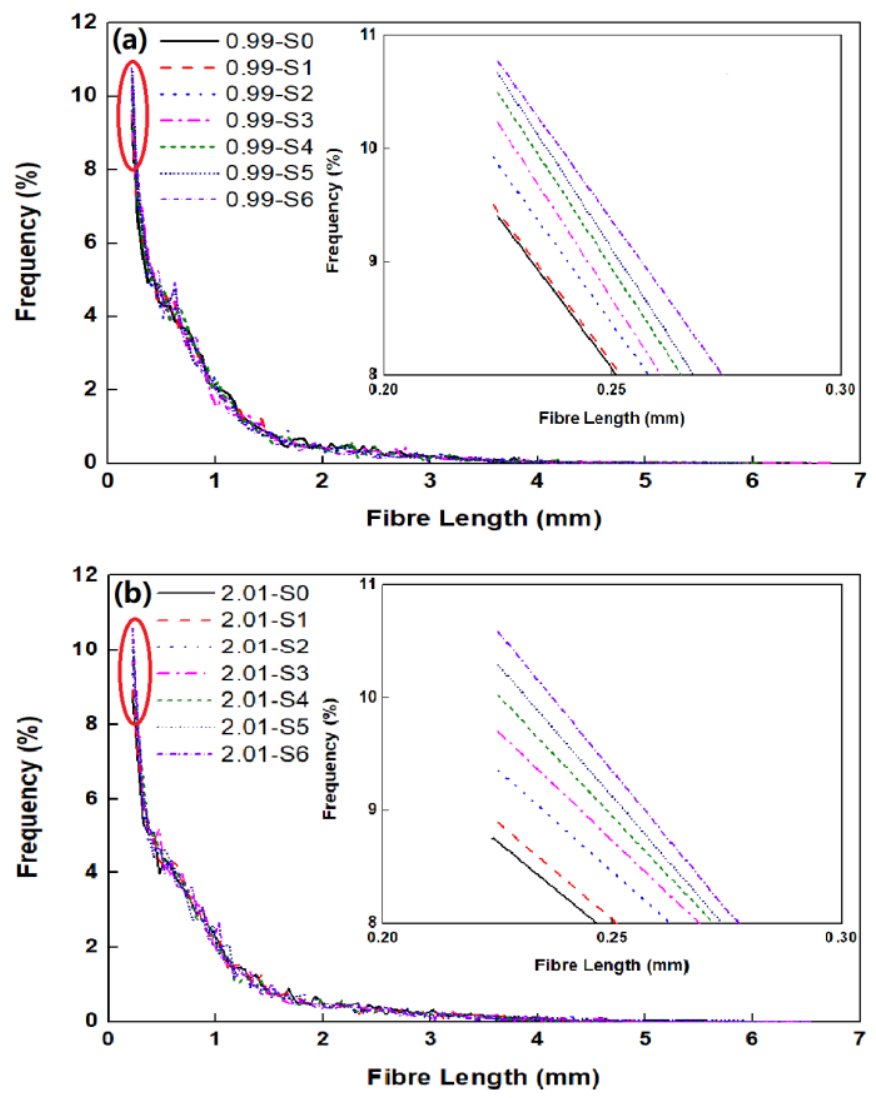

Fig. 3. The fibre length distribution of the AOCC pulp used in this research (SO, S1, S2, S3, S4, S5, and S6 at 0, 20, 40,60, 80, 100, and 120 total specific energy, respectively): (a) fibre length distribution of the AOCC pulp using $0.99 \mathrm{BEL}$ refining plate; (b) fibre length distribution of the AOCC pulp using 2.01 BEL refining plate

The fibre curl index, which is the ratio of the fibre contour length to the projected length ends minus one, is an assessment of the straightness of the fibre (Page and Seth 1980; Gion et al. 2011). The decrease of fibre curl has also been found to improve the tensile strength of the produced paper (Seth 2006). Figure 2c shows that the curl index of the refined AOCC pulp decreased for both interim 2.01 BEL and wide 0.99 BEL plates through increasing the refining energy. This is in agreement with a previous study on LC refining of chemical fibres (Mohlin and Alfredsson 1990). Additionally, compared to refining with $0.99 \mathrm{BEL}$ plate, the 2.01 BEL plate resulted in a much greater decrease of curl index under the same refining energy. One possible explanation might be that the fibres had more chance to pass through greater filling grooves $(0.99 \mathrm{BEL})$ rather than being trapped by the bars (Gharehkhani et al. 2015). In addition, the kink index of AOCC fibres decreased by increasing the refining energy (Fig. 2d), which further indicates that fibres were straightened by the refining treatment.

Figure 4 shows microscopic images of AOCC pulp fibres obtained from the refining at different energies with two different refining plates. 


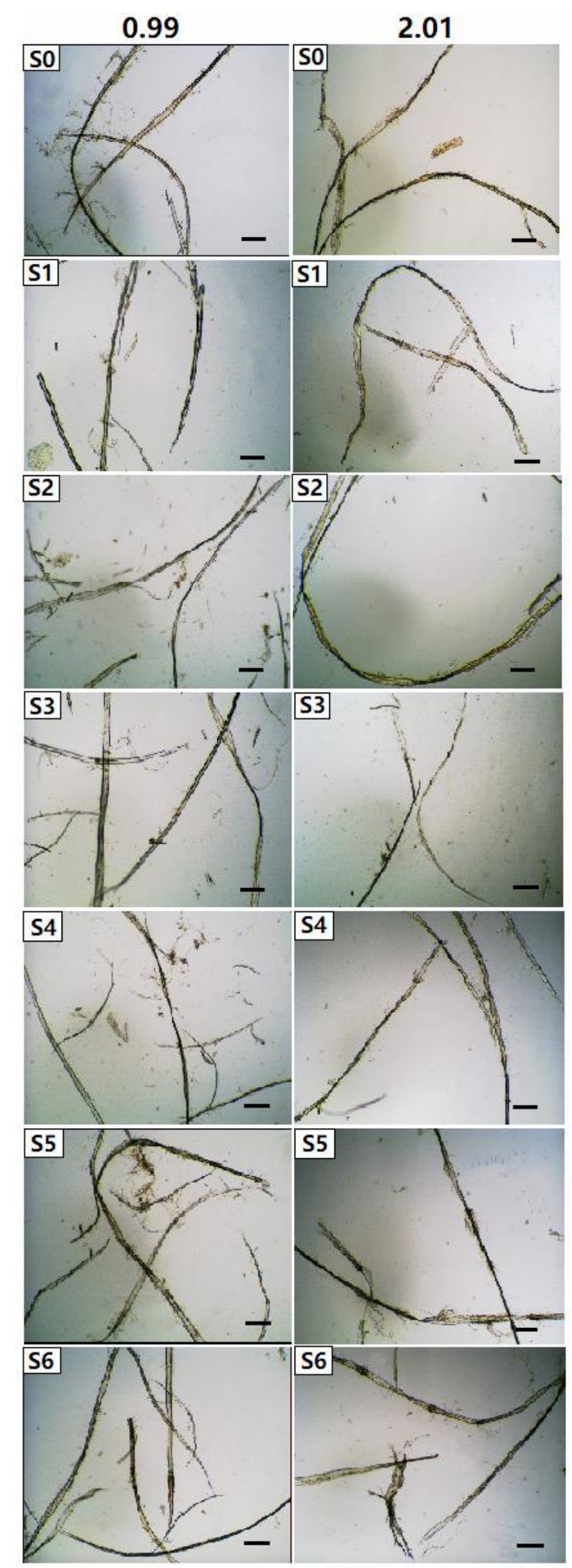

Fig. 4. Effects of mechanical refining on AOCC pulp fibres through 2.01 BEL and 0.99 BEL plates; SO, S1, S2, S3, S4, S5, and S6 at 0, 20, 40, 60, 80, 100, and 120 total specific energy, respectively; Scale bar $=50 \mu \mathrm{m}$ 
As shown in Fig. 4, the fibres became more fibrillated and flexible with increasing total SRE. The fibrillation made fine fibres loose, which yielded an amount of fine fibres and microfibrils. This resulted in a fast increased fines content. In addition, the length of fibres from both 2.01 BEL and 0.99 BEL plates gradually decreased with increasing SRE under the same magnitude ratio. Furthermore, the 2.01 BEL plate was not fibrillated to the same extent as the $0.99 \mathrm{BEL}$ plate during refining. This was the same for results obtained from the FQA experiments, the length of AOCC refined with the 2.01 BEL plate was longer than that of AOCC refined with the 0.99 BEL plate.

\section{Freeness}

Freeness, which represents the amount of water flowing through a bed of fibre network, is the most widely used control test in the stock preparation area of the paper mill. The freeness of AOCC pulp decreased with increasing refining energy input (Fig. 5), indicating that the refining process increased the fibrillation of fibres and created more short fibres. Moreover, the initial freeness was the same for both 2.01 BEL and 0.99 BEL plates; thereafter it changed slightly. Refining with the interim 2.01 BEL plate had slightly higher pulp freeness than the 0.99 plate at the same SRE (Fig. 5). The higher pulp freeness was related to longer fibre length and lower fines generated during LC refining (Fischer et al. 2017). Once more energy was transferred to the pulp suspension, a lower drop in freeness was observed.

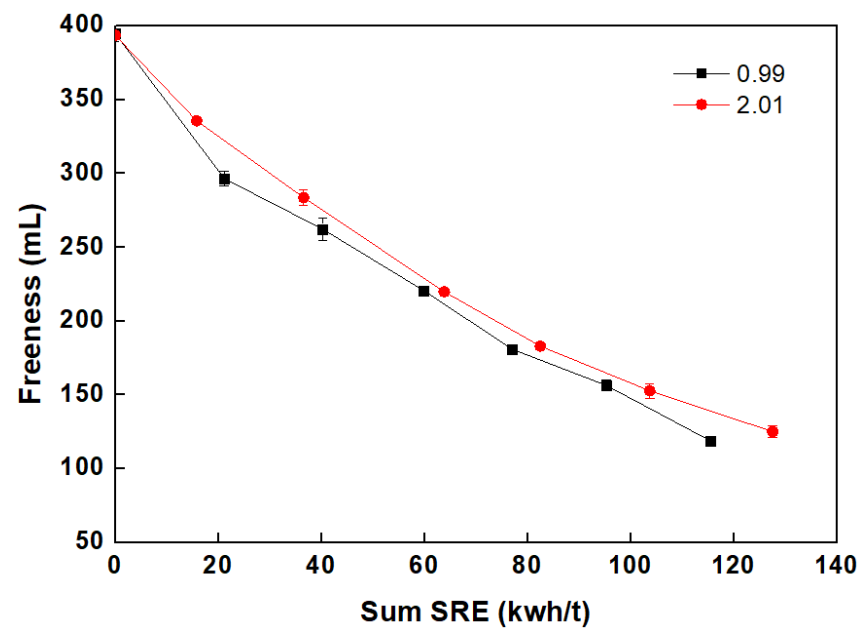

Fig. 5. The development of freeness versus sum SRE during LCR

\section{Tensile Strength Development}

To further evaluate the effect of LC refining with the two plates, the tensile strength of the obtained pulp was determined. As shown in Fig. 6, the tensile index of the obtained pulp initially increased with the increase of SRE used for LC refining, and thereafter the increase rate started to level off for both two plates. Although the refining could increase the fibrillation of fibres and the hydrogen bonding among fibres, the extensive refining caused a decrease in fibre length and generated more fines in the pulp suspension, which decreased the tensile strength of the pulp. Moreover, compared to the pulp made from the refining with the 2.01 BLE plate, the pulp obtained from the 0.99 BEL refining plate showed lower tensile strength (Fig. 6). For example, at a refining energy of $60 \mathrm{kWh} / \mathrm{t}$, the tensile indexes were 53.0 and $50.5 \mathrm{Nm} / \mathrm{g}(\mathrm{p} \leq 0.05)$ for 2.01 and 0.99 , respectively (Fig. 
6). The experimental results showed that with using the interim $2.01 \mathrm{~km} / \mathrm{rev}$ BEL plate, the tensile strength of the produced AOCC pulp increased from 39.5 to $57.0 \mathrm{Nm} / \mathrm{g}$ by increasing the refining energy from 0 to $127 \mathrm{kWh} / \mathrm{t}$, while for wide $0.99 \mathrm{~km} / \mathrm{rev}$ BEL plate, with increasing refining energy from 0 to $116 \mathrm{kWh} / \mathrm{t}$, the tensile strength of the obtained AOCC pulps increased from 38.0 to $46.9 \mathrm{Nm} / \mathrm{g}$.

Figure 6 also shows that at a given refining energy input, the interim plate 2.01 accomplished the higher tensile strength. Although at lower SRE, the difference of tensile strength between two plates was slight, but at higher SRE the effect of plate geometries on tensile strength became more obvious. This suggested that at the same refining energy, the treated AOCC fibres with the interim plate 2.01 BEL built up a stronger fibre network that resulted in higher tensile strength. This was different from the results obtained by Salim and Olson (2017), who investigated the tensile development of northern bleached softwood kraft pulp (NBSK) in a low consistency refiner. They concluded that there was no appreciable difference in the tensile development when refined by different bar geometries (wide, narrow). This distinction might be explained by the differences of the fibre structure between the two kinds of pulps and the difference of plate geometries involved.

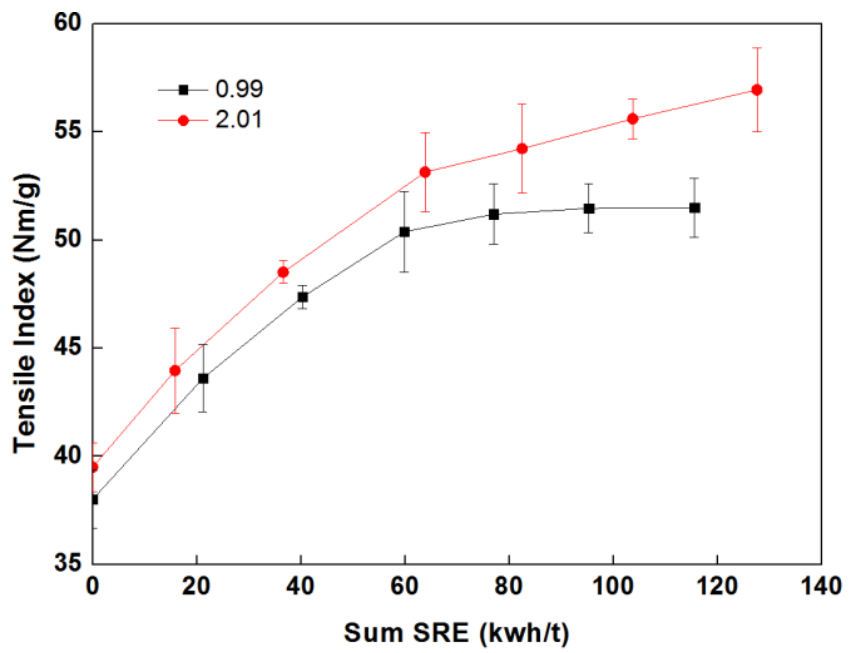

Fig. 6. Tensile strength as function of sum SRE at 1200 RPM

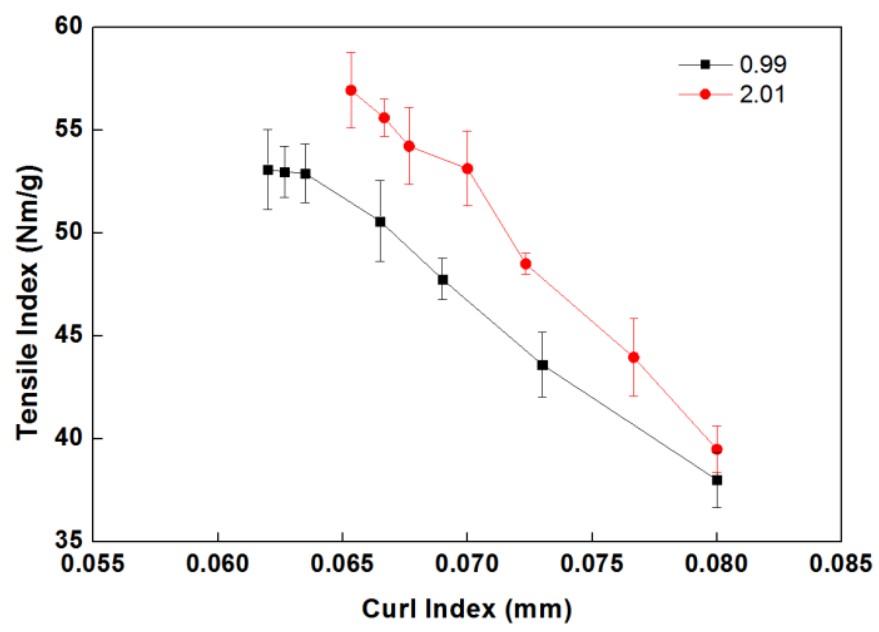

Fig. 7. Tensile strength as function of curl Index 
The effects of fibre deformations (curl and kinks) on tensile strength were also studied. Figure 7 shows the correlation between tensile development and curl index. As shown, the tensile strength decreased when the AOCC fibres in the fibre network were deformed. This could have been attributed to the fact that the deformed fibres (curl index, kink index) formed a fibre network where the load distribution was non-uniform (fibre activation was not uniform) compared to a situation with straight and un-deformed fibres. The nonuniform load distribution caused local stress points, which broke when fibre network was drawn and resulted in low tensile strength values (Zeng et al. 2012).

The correlation between freeness and tensile strength is shown in Fig. 8. As shown, the tensile strength was inversely proportional to the freeness, indicating that the refining process decreased the freeness and increased the tensile strength. The interim 2.01 BEL plate yielded higher tensile strength than the wide 0.99 BEL plate. The higher tensile index at a given freeness with the 2.01 BEL plate was probably related to the observation that this treatment produced pulps with longer fibre length and lower fines content compared to the 0.99 BEL plate. As clearly shown, the difference of tensile index between two plates was larger at lower freeness than higher freeness of the refined pulp. For example, at the freeness value of $130 \mathrm{~mL}$ Canadian standard freeness (CSF), the tensile indexes were 53.0 $\mathrm{Nm} / \mathrm{g}$ and $56.8 \mathrm{Nm} / \mathrm{g}$ for 0.99 BEL plate and 2.01 BEL plate, respectively. In contrast, at the pulp freeness of $350 \mathrm{~mL} \mathrm{CSF}$, the tensile difference between two plates was $2.7 \mathrm{Nm} / \mathrm{g}$ (40.1 Nm/g for $0.99 \mathrm{BEL}$ plate and $42.8 \mathrm{Nm} / \mathrm{g}$ for $2.01 \mathrm{BEL}$ plate). It was also noticed from Fig. 8 that in the range of low freeness (lower than $180 \mathrm{~mL} \mathrm{CSF}$ ), the tensile strength decreased slowly with increasing freeness. By contrast, in range of high freeness (higher than $180 \mathrm{~mL} \mathrm{CSF}$ ), the tensile strength was reduced rapidly.

This work preliminarily compared the effect of LC refining with wide $0.99 \mathrm{~km} / \mathrm{rev}$ BEL plate and interim $2.01 \mathrm{~km} / \mathrm{rev}$ BEL plate on the pulp properties and tensile strength of AOCC pulp. The refining intensities of $0.24 \mathrm{~J} / \mathrm{m}$ and $0.48 \mathrm{~J} / \mathrm{m}$ were investigated for the 2.01 BEL plate and the 0.99 BEL plate, respectively. Based on the preliminary results, interim $2.01 \mathrm{~km} / \mathrm{rev}$ BEL plate is considered to be suitable for the refining of AOCC pulp. To provide deep understanding of the refining of AOCC pulp, further work will be focused on the refining of AOCC pulp with interim $2.01 \mathrm{~km} / \mathrm{rev}$ BEL at different intensities and investigate the effect of the refining process on the fibre properties, including fibre length, fines content, curl, and kink.

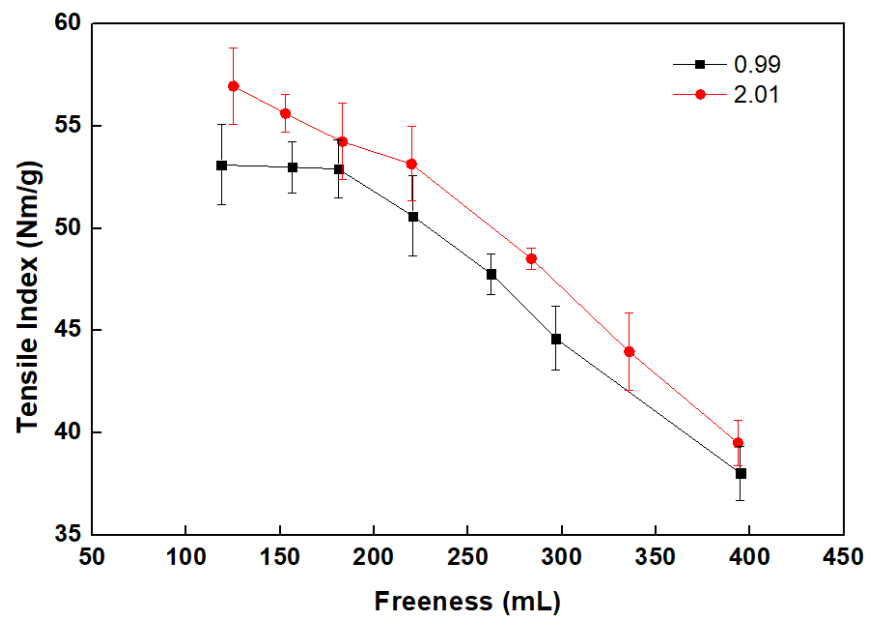

Fig. 8. Tensile strength as function of freeness 


\section{CONCLUSIONS}

The fibre properties, freeness, tensile strength, and refining energy input were determined during the $\mathrm{LC}$ refining process of American old corrugated container (AOCC) pulp with two different refiner plate patterns.

1. During LC refining with both interim $2.01 \mathrm{~km} / \mathrm{rev}$ BEL and wide $0.99 \mathrm{~km} / \mathrm{rev}$ BEL plates, with increasing the SRE, the fibre length, curl index, kink index, and freeness values of the pulp decreased, while fines content and tensile strength of the produced handsheets increased.

2. LC refining with $2.01 \mathrm{BEL}$ plate at low intensity of $0.24 \mathrm{~J} / \mathrm{m}$ showed less reduction in fibre length than that obtained with 0.99 BEL plate at an intensity of $0.48 \mathrm{~J} / \mathrm{m}$ when refining at the same specific energy.

3. Under the same SRE, refining with $2.01 \mathrm{~km} / \mathrm{rev}$ BEL plate generally resulted in higher fibre length, curl index, freeness, and tensile strength of AOCC pulp than the refining with $0.99 \mathrm{~km} / \mathrm{rev}$ BEL plate.

4. Compared to the wide $0.99 \mathrm{~km} / \mathrm{rev}$ BEL plate, less energy was required for the interim $2.01 \mathrm{~km} / \mathrm{rev}$ BEL plate to achieve a given tensile strength of AOCC pulp. Moreover, the interim $2.01 \mathrm{~km} / \mathrm{rev}$ BEL plate achieved higher tensile strength than $0.99 \mathrm{~km} / \mathrm{rev}$ BEL plate at the same pulp freeness.

\section{ACKNOWLEDGMENTS}

This work was funded by the Priority Academic Program Development of Jiangsu Higher Education Institutions (PAPD), and National Major Science and Technology Program for Water Pollution Control and Treatment (2017ZX07402004). Special thanks go to Reanna Seifert and George Soong (Pulp and Paper Centre, University of British Columbia). Professor James A. Olson and Robert Gooding are acknowledged for their valuable advice and support during the trials.

\section{REFERENCES CITED}

Bajpai, P. (2015). "Chapter 3: Pulp and paper chemicals," in Pulp and Paper Industry, Elsevier, Amsterdam, Netherlands, pp. 103-154. DOI: 10.1016/B978-0-12-8034088.00003-2

Cai, H., Yuan, Z., Zhang, X., Jun, S., Zhang, H., and Olson, J. (2017). "The influence of consistency and fibre length on the yield stress of OCC pulp fibre suspensions," BioResources 12(4), 8368-8377. DOI: 10.15376/biores.12.4.8368-8377

Fernandes Diniz, J. F. B., Gil, M. H., and Castro, J. A. A. A. M. (2004). "Hornificationits origin and interpretation in wood pulps," Wood Science and Technology 37(6), 489-494. DOI: 10.1007/s00226-003-0216-2

Fischer, W. J., Mayr, M., Spirk, S., Reishofer, D., Jagiello, L. A., Schmiedt, R., Colson, J., Zankel, A., and Bauer, W. (2017). "Pulp fines-characterization, sheet formation, and comparison to microfibrillated cellulose," Polymers 9(8), 1-12. DOI: 10.3390/polym9080366 
Gharehkhani, S., Sadeghinezhad, E., Kazi, S. N., Yarmand, H., Badarudin, A., Safaei, M. R., and Zubir, M. N. M. (2015). "Basic effects of pulp refining on fiber properties - A review," Carbohydrate Polymers 115, 785-803. DOI: 10.1016/j.carbpol.2014.08.047

Gion, J. M., Carouché, A., Deweer, S., Bedon, F., Pichavant, F., Charpentier, J. P., Baillères, H., Rozenberg, P., Carocha, V., and Ognouabi, N. (2011). "Comprehensive genetic dissection of wood properties in a widely-grown tropical tree: Eucalyptus," BMC Genomics 12(1), 301-312. DOI: 10.1186/1471-2164-12-301

Gominho, J., and Pereira, H. (1995). "67-the effect of refining in the fibre structure and properties in unbleached eucalypt pulps," Cellulose and Cellulose Derivatives 1995, 529-534. DOI: 10.1533/9781845698539.6.529

Gorski, D., Hill, J., Engstrand, P., and Johansson, L. (2010). "Reduction of energy consumption in TMP refining through mechanical pre-treatment of wood chips," Nordic Pulp \& Paper Research Journal 25(2), 156-161. DOI: 10.3183/NPPRJ-201025-02-p156-161

Gorski, D., Mörseburg, K., Olson, J. A., and Luukkonen, A. (2012). "Fibre and fines quality development in pilot scale high and low consistency refining of ATMP," Nordic Pulp \& Paper Research Journal 27(5), 872-881 DOI: 10.3183/NPPRJ-201227-05-p872-881

Gurnagul, N. (1995). "Sodium hydroxide addition during recycling: Effects on fiber swelling and sheet strength," TAPPI Journal 78(12), 119-124.

Hubbe, M. A., Venditti, R. A., and Rojas, O. J. (2007). "What happens during cellulosic fibres during papermaking and recycling? A review," BioResources 2(4), 739-788. DOI: $10.15376 /$ biores.2.4.739-788

Hunt, J. F., and Vick, C. B. (2004). "Evaluation of coupling agents to manufacture hybrid hardboard made from industrial waste fiberglass and wood fiber," Forest Products Journal 54(7-8), 35-41.

Ingmanson, W. L., and Thode, E. F. (1959). "Factors contributing to the strength of a sheet of paper," TAPPI Journal 42(1), 83-93.

Kang, T. Y., Youn, H. J., and Lee, H. L. (2017). "Effects of fractionation and mechanical treatments of Korean OCC on paper properties," Nordic Pulp \& Paper Research Journal 32(1), 148-154. DOI: 10.3183/NPPRJ-2017-32-01-p148-154

Kerekes, R. J. (1990). “Characterization of pulp refiners by a C-factor," Nordic Pulp \& Paper Research Journal 5(1), 3-8. DOI: 10.3183/NPPRJ-1990-05-01-p003-008

Lumiainen, J. (1990). "A new approach to the critical factors affecting on refining intensity and refining result in low consistency refining," in: Proceedings of the TAPPI Papermakers Conference, Atlanta, GA, USA, pp. 6-15.

Mohlin, U. B., and Alfredsson, C. (1990). "Fibre deformation and its implications in pulp characterization," Nordic Pulp \& Paper Research Journal 5(4), 172-179. DOI: 10.3183/NPPRJ-1990-05-04-p172-179

Muenster, H., Ferritsius, O., Lecourt, M., and Petit-Conil, M. (2005). "Energy savings in TMP by high temperature LC/MC refining," in: International Mechanical Pulping Conference 2005, Minneapolis, USA, pp. 1-10.

Nugroho, D. D. P. (2012). Low Consistency Refining of Mixtures of Softwood \& Hardwood Bleached Kraft Pulp: Effects of Refining Power, Master's Thesis, Asian Institute of Technology, Bangkok, Thailand.

Oliveux, G., Dandy, L. O., and Leeke, G. A. (2015). "Current status of recycling of fibre reinforced polymers: Review of technologies, reuse and resulting properties," Progress in Materials Science 72, 61-99. DOI: 10.1016/j.pmatsci.2015.01.004 
Olson, J. A., Drozdiak, J., Martinez, M., Garner, R., Robertson, A. G., and Kerekes, R. (2003). "Characterizing fibre shortening in low-consistency refining using a comminution model," Powder Technology 129(1-3), 122-129. DOI: 10.1016/S00325910(02)00129-8

Page, D. H., and Seth, R. S. (1980). "The elastic modulus of paper III. The effects of dislocations, microcompressions, curl, crimps, and kinks," TAPPI Journal 63(10), 99102.

Prairie, B., Wild, P., Byrnes, P., Olender, D., Francis, B., and Ouellet, D. (2008). "Forces during bar-passing events in low-consistency refining: Distributions and relationships to specific edge load," Journal of Pulp and Paper Science 34(1), 1-8.

Rubiano Berna, J. E., Martinez, D. M., and Olson, J. A. (2018). "A comminution model parametrization for low consistency refining," Powder Technology 328, 288-299. DOI: 10.1016/j.powtec.2018.01.031

Sain, M., Fortier, D., and Lampron, E. (2002). "Chemi-refiner mechanical pulping of flax shives: Refining energy and fibre properties," Bioresource Technology 81(3), 193200. DOI: $10.1016 / \mathrm{s} 0960-8524(01) 00143-2$

Salim, S., and Olson, J. (2017). "On the net refining energy and tensile development of nbsk pulp in a low consistency refiner," Nordic Pulp \& Paper Research Journal 32(1), 110-118. DOI: 10.3183/NPPRJ-2017-32-01-p110-118

Seth, R. S. (2006). "The importance of fibre straightness for pulp strength," Pulp and Paper Canada 107(1), 34-42.

Sixta, H. (2008). Handbook of Pulp, Wiley-VCH Verlag GmbH \& Co. KGaA, Weinheim, Germany, pp. 86-122, DOI: 10.1002/9783527619887

Sjoberg, J. C., and Hoglund, H. (2007). "High consistency refining of kraft pulp for reinforcing paper based on TMP furnishes," in: International Mechanical Pulping Conference 2007, Minneapolis, MN, USA, pp. 943-953.

Smith, S. (1922). "The action of the beater in papermaking: With special reference to the theory of the fibarge and its application to old and new problems of beater design," Journal of the Royal Society of Arts 71, 38-56.

Viesturs, U., Leite, M., Treimanis, A., Eremeeva, T., Apsíte, A., Eisimonte, M., and Uansons, P. (1996). "Production of cellulases and xylanases by Trichoderma viride and biological processing of lignocellulose and recycled paper fibers," in: Seventeenth Symposium on Biotechnology for Fuels and Chemicals, Volume 57/58, Humana Press, Totowa, NJ, USA, pp. 349-360, DOI: 10.1007/978-1-4612-02233_30

Wultsch, F., and Flucher, W. (1958). "The Escher-Wyss small refiner as a standard test apparatus for modern stock preparation plants," Das Papier 12(13-14), 334-342.

Zeng, X. L., Retulainen, E., Heinemann, S., and Fu, S. Y. (2012). "Fibre deformations induced by different mechanical treatments and their effect on zero-span strength," Nordic Pulp \& Paper Research Journal 27(2), 335-342. DOI: 10.3183/NPPRJ-201227-02-p335-342

Article submitted: August 7, 2019; Peer review completed: October 26, 2019; Revised version received: November 12, 2019; Further revised version accepted: November 16, 2019; Published: November 21, 2019.

DOI: $10.15376 /$ biores.15.1.347-359 